\title{
Rediscovery, redescription and reclassification of Beludzhia phylloteliptera (Diptera: Sarcophagidae: Miltogramminae)
}

\author{
KRZYSZTOF SZPILA ${ }^{1}$ and ThOMAs PAPE ${ }^{2}$ \\ ${ }^{1}$ Nicolaus Copernicus University, Institute of Ecology and Environmental Protection, Department of Animal Ecology, Gagarina 9, \\ 87-100 Toruń, Poland; e-mail: szpila@biol.uni.torun.pl \\ ${ }^{2}$ Zoological Museum, Universitetsparken 15, 2100 Copenhagen, Denmark; e-mail: tpape@snm.ku.dk
}

Key words. Sarcophagidae, Miltogramminae, redescription, systematics, larva, adult, morphology, SEM, Beludzhia, Dolichotachina, Phylloteles

\begin{abstract}
The species Beludzhia phylloteliptera Rohdendorf is redescribed from adult males and females as well as all larval instars collected in the United Arab Emirates. The morphology of the first instar larva is strikingly similar to that of Dolichotachina marginella (Wiedemann) and Phylloteles pictipennis Loew, all of which are here documented for the first time. These three generic representatives share several character states, which are probably plesiomorphic relative to the condition observed in other miltogrammine larvae, but the uniquely shaped, slender mouthhook, a cushion- or pad-like lobe behind the maxillary palpus (cheek organ), the antero-ventral segmental prolegs of the first instar larva, and the integumental warts of the third instar larvae, are shared character states not known from any other species of Sarcophagidae. Beludzhia Rohdendorf is therefore placed with Dolichotachina Villeneuve and Phylloteles Loew in the tribe Phyllotelini.
\end{abstract}

\section{INTRODUCTION}

Species of the flesh fly subfamily Miltogramminae are biologically interesting in that the large majority are kleptoparasites in the nests of solitary aculeate Hymenoptera (Spofford et al., 1989; Pape, 1996). This biological association has apparently spurred a remarkable morphological diversification of the first instar larva (Szpila \& Pape, 2005a, b). In spite of this, the monophyly of the subfamily as well as the generic classification has traditionally been based exclusively on non-larval features (Rohdendorf, 1967; Verves, 1989, 1994; Pape, 1996). Miltogrammine larval morphology is still known in greater detail for only a small minority of genera and species (Thompson, 1921; Szpila \& Pape, 2005a,b), but it is evident that larval morphology is unusually diverse (at least compared to the remaining Sarcophagidae) and bears a great potential for complementing the adult characters in phylogenetic analyses. The present study grew out of ongoing research on the morphology of miltogrammine larvae and was stimulated by the discovery and capture of Beludzhia phylloteliptera Rohdendorf, 1935 in the United Arab Emirates. This species was previously known only from the partly damaged male holotype from Iranian Beluchistan. A unique combination of spotted wings and long antennae with an elongated second aristomere were Rohdendorf's (1935) main reasons for erecting the monotypic genus Beludzhia. Subsequently published hypotheses of phylogenetic affinity have suggested a sister group relationship to either Oebalia RobineauDesvoidy, 1863 or Apodacra Macquart, 1854 (Rohdendorf, 1967 and Verves, 1989 respectively), although evidence supporting these hypotheses has not been provided. The aim of the present paper is to provide a thor- ough description of the species Beludzhia phylloteliptera, including both sexes and all larval instars, and place this taxon in a systematics context. To facilitate the discussion, we are also providing SEM images and short descriptions of the hitherto unknown larvae of Dolichotachina marginella (Wiedemann, 1830) and Phylloteles pictipennis Loew, 1844.

\section{MATERIAL AND METHODS}

Larval material was obtained by keeping wild-caught females under laboratory conditions. Females were collected in northern Poland (Phylloteles pictipennis) and the United Arab Emirates (Beludzhia phylloteliptera, Dolichotachina marginella) and identified using the keys of Rohdendorf $(1935,1975)$ as well as the reference collection of the Zoological Museum, Copenhagen (ZMUC). To obtain larvae, freshly caught females were kept individually in $50 \mathrm{ml}$ plastic vials with a layer of filter paper on the bottom (P. pictipennis) or $3 \mathrm{ml}$ Eppendorf tubes (B. phylloteliptera and D. marginella) with a finely perforated cover. During the following days, females, if gravid, spontaneously and repeatedly larviposited, and the first instar larvae were immediately collected and processed as explained below. After the death of the females, additional larvae were extracted from their abdomen by carefully cutting the membrane between segments VI and VII and gently squeezing the abdomen. All females were subsequently pinned and labelled (deposited in coll. Szpila and ZMUC).

Larvae were killed by soaking in hot water (about $95^{\circ} \mathrm{C}$ ) to extend the pseudocephalon and avoid subsequent deformation when stored in $80 \%$ alcohol. In case of ample offspring, a number of larvae were offered food in an attempt to rear them to older instars, which were killed and preserved in the same way as the first instars. For feeding were used freshly killed bees (Apis mellifera Linnaeus, 1758) and bumblebees (Bombus Latreille, 1802) in the case of $P$. pictipennis, while first instar larvae of $B$. phylloteliptera, which started to feed inside the 
dead body of their mother, were offered freshly killed specimens of blow flies (Chrysomya albiceps (Wiedemann, 1819)). Beside second and third instar larvae also two adult flies of $B$. phylloteliptera (male and female) were reared.

Preserved larvae were slide-mounted in Hoyer's medium for light microscopy. For first and second instars and the cephaloskeleton of the third instar, concave slides were used. Flat slides were used for other structures of the third instar. Preparation for SEM involved dehydration through 80,90 and $99.5 \%$ ethanol and either critical-point drying in $\mathrm{CO}_{2}$ (B. phylloteliptera, $D$. marginella) or soaking for $2 \times 30 \mathrm{~min}$ in hexamethyldisilazane (HMDS) followed by air-drying under a fume hood (P. pictipennis). The larvae were eventually sputter-coated with platinum (B. phylloteliptera, D. marginella) or carbon (P. pictipennis), and SEM pictures were taken with the use of a HITACHI S-4700 scanning microscope (Figs 23-36) and a JEOL JSM $6335 \mathrm{~F}$ field emission microscope (other SEM pictures). Illustrations were produced (by KS) from photographs made with the use of a digital Axiocam HRc camera mounted on a Zeiss Axioskop 2 plus microscope.

Material examined has been deposited in the following institutions: ZMUC - Zoological Museum, University of Copenhagen, Denmark; IEEP - Institute of Ecology and Environmental Protection, Nicolaus Copernicus University, Toruń, Poland; MZIW - Museum and Zoological Institute, Polish Academy of Sciences, Warsaw, Poland.

\section{Terminology}

Adult terminology follows Merz \& Haenni (2000), except that we use setae rather than macrotrichia as the general term for the socket-based, more or less hair-like, projections of the exoskeleton (Kristensen \& Simonsen 2003; Garm, 2004), and bristle is used to denote a particularly strong seta. Larval terminology follows Courtney et al. (2000) with a few modifications proposed by Szpila \& Pape (2005a) and as discussed further below.

Cheek organ: On the pseudocephalon of the first instar larva, laterally to the maxillary palpus, a small sensillum (rarely two) may be visible. When the sensillum is situated on a cushion- or pad-like lobe, we call the combined structure the cheek organ (Figs 1, 2, 5, 6, 16, 17, 24, 27, 28). We have not observed this sensillum or the combined cheek organ containing it in larvae outside the Miltogramminae.

Maxillary palpus: As described by Szpila \& Pape (2005a,b), the miltogrammine maxillary palpus has a cluster of six large sensilla. Three of these are sensilla coeloconica, i.e., placed in a distinct socket, the other three are sensilla basiconica, i.e., without a socket. On the periphery of maxillary palpus there are two additional sensilla coeloconica with non-maxillary origin (Courtney et al., 2000). Such number and types of sensilla and their arrangement appear to be widespread in the Calyptratae (Courtney et al., 2000; Szpila, 2003, 2004), and in order to be able to refer specifically to particular sensilla of the maxillary cluster, we propose the numbering system shown in Fig. 4.

Prolegs: Courtney et al. (2000) defined prolegs as fleshy, paired structures, while the single, swollen, transverse ridges were termed creeping welts. Prolegs occur scattered throughout the Diptera in a multitude of shapes (Courtney et al., 2000, Table 4.2), and the term proleg (like creeping welt) is more a functional one than one of homology. We see no convincing arguments for restricting the term proleg to paired structures, and we here propose to use the term proleg for the following different types of (unpaired) protuberances found in miltogrammine larvae, each of which is considered a case of primary homology argued from the similarity in position:
(1) anterior proleg: situated at the antero-ventral margin of a segment and may as such be positioned on a creeping welt (see below);

(2) pre-crevice proleg: situated ventrally and immediately anterior to the transverse crevice centrally on a segment;

(3) post-crevice proleg: situated ventrally and immediately posterior to the transverse crevice centrally on a segment;

(4) dorsal proleg: situated dorso-centrally on a segment.

Creeping welts: For reasons of homogeneity we follow Courtney et al. (2000) in their use of the term creeping welt, but restrict the use of this term to the well-delimited structures that we previously have called intersegmental insertions (Szpila \& Pape, 2005b). Creeping welts in the Miltogramminae appear to be arranged along the anterior part of a segment, and they can be present ventrally as well as laterally.

Spiracular distance factor: This relative measure was introduced by Emden (1965) and is calculated by dividing the shortest distance between the posterior spiracles by the greatest diameter of one spiracle (Fig. 61, SDF $=\mathrm{A} / \mathrm{B}$ ). The SDF has significant diagnostic value in the third instar larvae of many Calliphoridae (Erzinçlioğlu, 1985; Draber-Mońko, 2004). However Wallman (2001) mentioned that SDF may be affected by cuticular shrinkage due to preservation and should be measured only in fresh specimens.

\section{RESULTS}

\section{Beludzhia phylloteliptera Rohdendorf, 1935.}

Type locality. Iran, Beluchistan, between Lajadis and DusAbad. Holotype male in Zoological Institute, St Petersburg [not examined]; upper half of left eye destroyed.

Material examined. United Arab Emirates: 10, Fujairah Emirate, Wadi Warayah, 11.-15.iv.2005, T. Pape \& K. Szpila (ZMUC); 7ठ, 8오. Ajman Emirate, Huwaylat, 15.-17.iv.2005, T. Pape \& K. Szpila (ZMUC, IEEP, MZIW); $10^{\star}$ Fujairah Emirate, Tayyibah, 13.-14.iv.2005, K. Szpila (IEEP). Several larvae of all instars (89 first instar, 2 second instar, 4 third instar; in coll. Szpila).

Male (Figs 80, 82). Head. Parafacial plate strongly receding, giving the head a triangular profile. Frontal stripe with silvery grey microtrichosity, black colour of integument visible through the microtrichiae particularly in the anterior part. Fronto-orbital and parafacial plates with dense silvery microtrichosity. Scape, pedicel and flagellomere 1 blackish, arista dark brown. Ocellar triangle with a pair of latero-proclinate bristles about the size of a medium-sized frontal seta. A few additional ocellar setulae, one pair of post-ocellar bristles. Inner vertical bristles strong, outer verticals $0.5 \times$ as long as the inner verticals. Numerous frontal setae with the weakest situated between lunule and the anteriormost proclinate orbital setae. Frontal stripe and vertex bare. Three proclinate orbital setae, 1-3 setulae around the uppermost proclinate orbital, fronto-orbital plate otherwise bare. Parafacial plate bare. Lunule bare. Scape and pedicel clothed with short setae, pedical bristle short. Gena and postgena with white setulae, postcranium with sparse, blackish setulae. Antenna inserted at level of middle of eye. Flagellomere 1 about as long as arista and reaching level of lower eye-margin. Arista micropubescent; aristomeres 1 and 2 distinctly elongated, aristomere 1 twice as long as broad, aristomere 2 three times as long as broad (distal diameter), aristomere 3 thickened (i.e., as thick as 

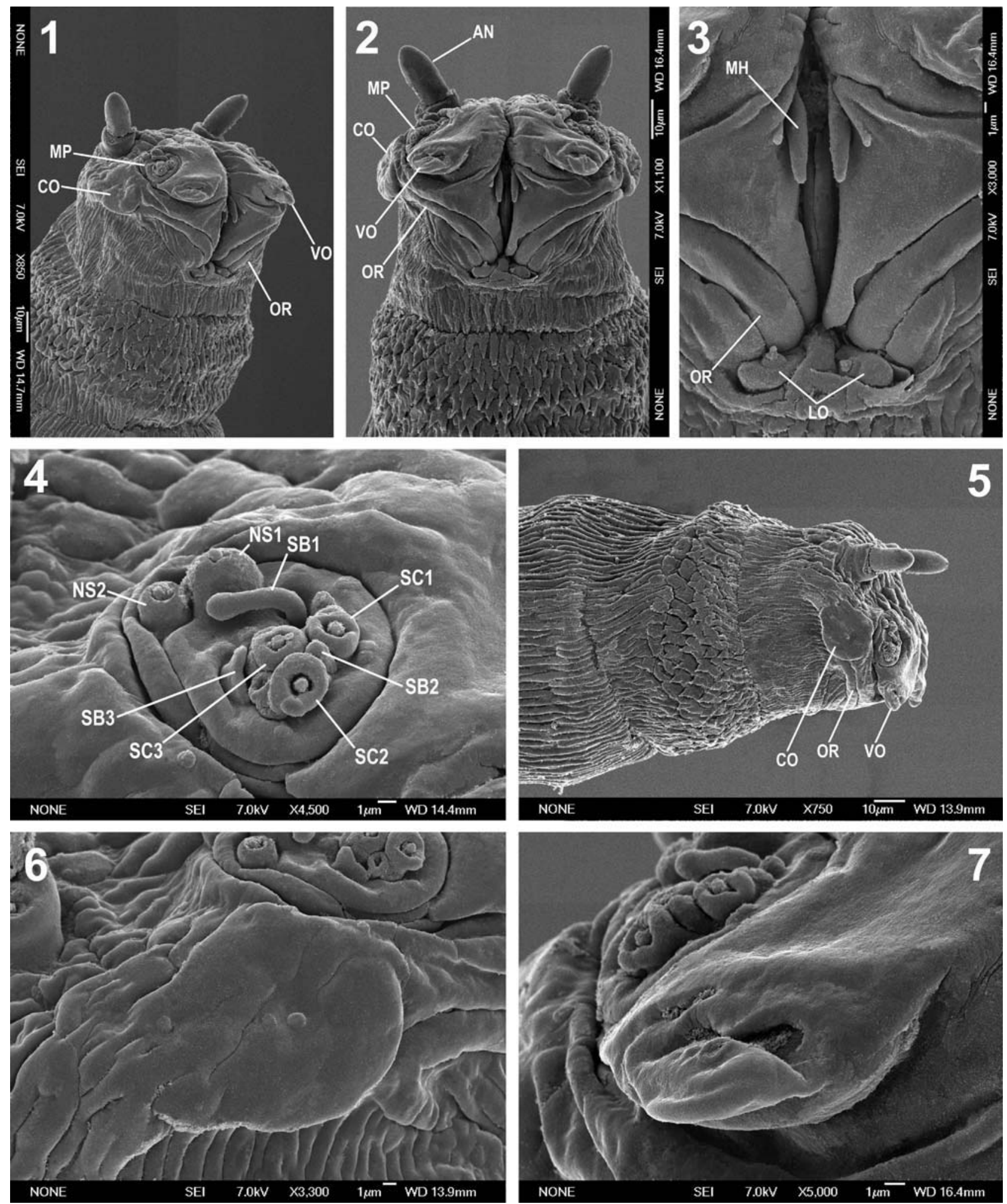

Figs 1-7. First instar larva of Beludzhia phylloteliptera: 1 - anterior end, antero-lateral view; 2 - anterior end, ventral view; 3 functional mouth opening; 4 - maxillary palpus; 5 - anterior end, lateral view; 6 - cheek organ; 7 - ventral organ. Abbreviations: AN - antennal socket sensilla, CO - cheek organ, LO - labial organ, MH - mouthhook, MP - maxillary palpus, NS1 - first additional sensillum coeloconicum, NS2 - second additional sensillum coeloconicum, OR - oral ridges; SB1 - first sensillum basiconicum, SB2 - second sensillum basiconicum, SB3 - third sensillum basiconicum, SC1 - first sensillum coeloconicum, SC2 - second sensillum coeloconicum, $\mathrm{SC} 3$ - third sensillum coeloconicum, $\mathrm{VO}$ - ventral organ.

distal part of antennomere 2) in proximal 0.7 and very slightly compressed. Facial plate with a very low but dis- tinct keel below the antennal insertion. Vibrissal angle with well developed vibrissa, a single supravibrissal seta, 

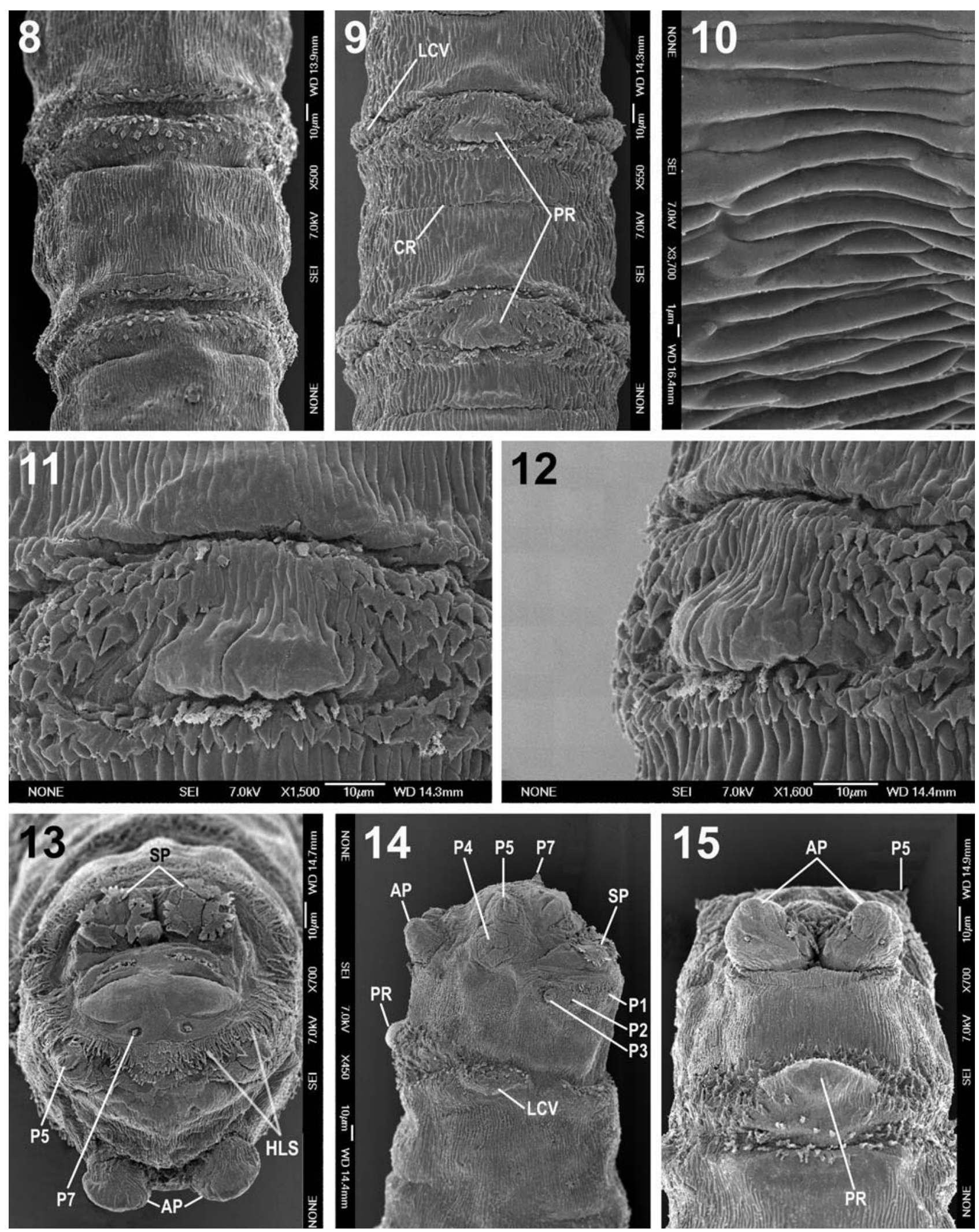

Figs 8-15. First instar larva of Beludzhia phylloteliptera: 8 - AIV, dorsal view; 9 - AII, ventral view; 10 - cuticular ridges; 11 proleg, ventral view; 12 - proleg, latero-ventral view; 13 - posterior end, posterior view; 14 - posterior end, lateral view; 15 - posterior end, ventral view. Abbreviations: AP - anal papillae, CR - transverse crevice, HLS - hair-like spines, LCV - lateral creeping velt, P1 - dorsal papillae, P2 - subdorsal papillae, P3 - supralateral papillae, P4 - infralateral papillae, P5 - subventral papillae, P7 supraventral papillae, $\mathrm{PR}$ - proleg, $\mathrm{SP}$ - spiracles. 

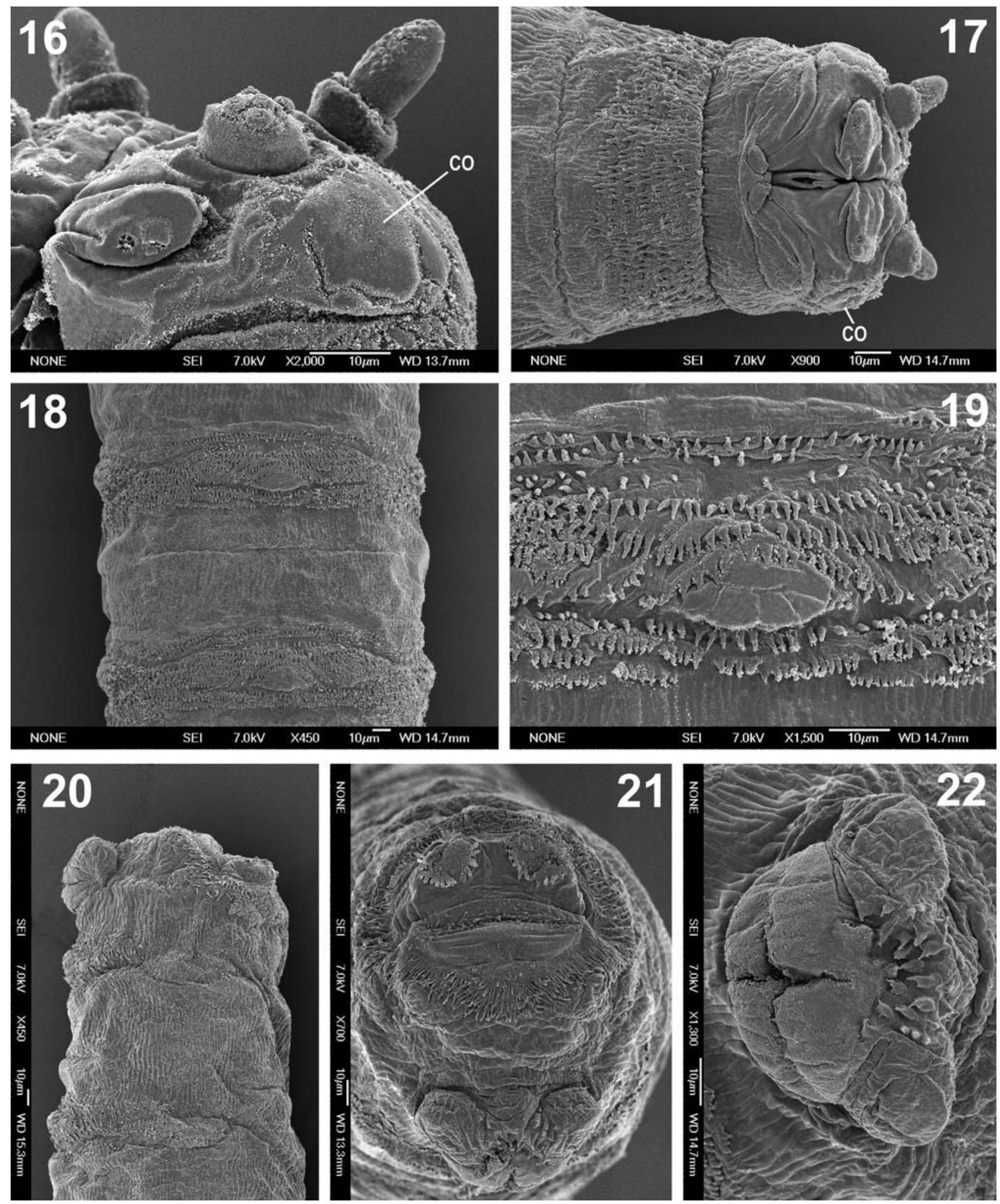

Figs 16-22. First instar of Dolichotachina marginella: 16 - left lobe of pseudocephalon, ventro-lateral view; 17 - anterior end, ventral view; 18 - AIV, ventral view; 19 - proleg, ventral view; 20 - posterior end, lateral view; 21 - posterior end, posterior view; 22 - anal opening. Abbreviations: $\mathrm{CO}$ - cheek organ.

and 4-6 peristomal bristles; vibrissa shorter than distance between vibrissae and only slightly stronger than the anteriormost peristomal bristle. Gena as high as greatest lateral width of flagellomere 1. Proboscis short, about as long as palpus; palpus yellow.

Thorax. Black ground colour; covered with dense, gray microtrichosity; three black stripes visible on scutum in 

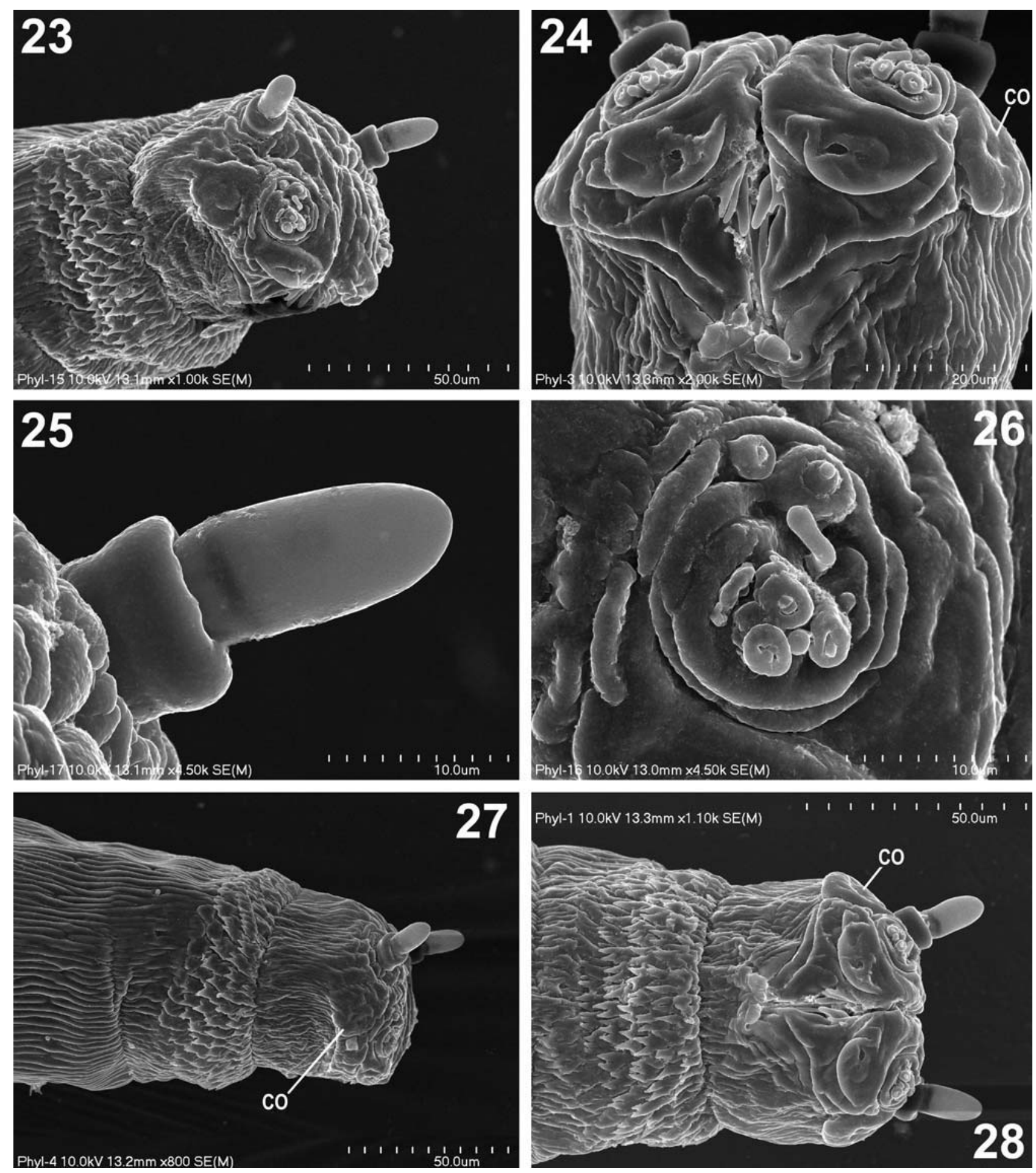

Figs 23-28. First instar of Phylloteles pictipennis: 23 - anterior end, antero-lateral view; 24 - pseudocephalon, ventral view; 25 antenna; 26 - maxillary palpus; 27 - anterior end, lateral view; 28 - anterior end, ventral view. Abbreviations: $\mathrm{CO}$ - cheek organ.

anterior view, fading from the transverse suture and not reaching scutellum. Chaetotaxy: acrostichals $0(-1)+1$, dorsocentrals $2+3$, intra-alars $1+1$, supra-alars $1+2$, postalars 2; proepisternum (depressed part of propleuron) bare, postpronotum with two bristles, notopleuron with 0-3 setulae in addition to the usual two notopleurals; scutellum with two pair of laterals, one pair of apicals, with or without a pair of weak discals.
Legs. Foretarsus with tarsomeres 1-4 distally equipped with a slender, hair-like (sensory?) antero-dorsal and postero-dorsal setae. Foretibia with bristles only distally; midtibia with one antero-ventral and one anterodorsal bristle, 1-2 weak posterodorsal and one posterior bristle; hindtibia with one anteroventral bristle, a row of anterodorsals and 2-4 posterodorsal bristles of irregular size. Claws less than half as long as tarsomere 5. Legs otherwise without particular setal modifications. 

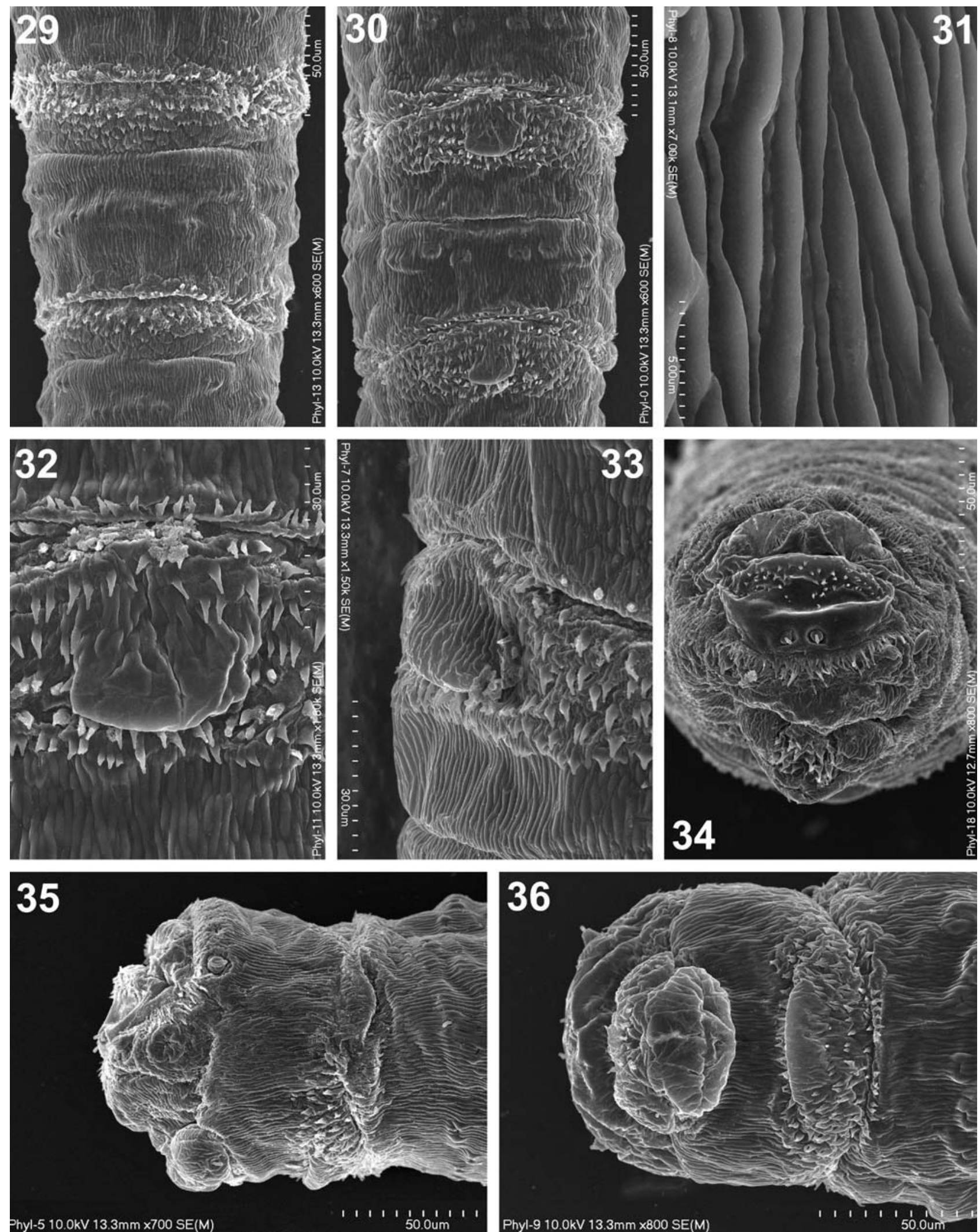

Figs 29-36. First instar of Phylloteles pictipennis: 29 - AV, dorsal view; 30 - AIV, ventral view; 31 - cuticular ridges; 32 proleg, ventral view; 33 - proleg, latero-ventral view; 34 - posterior end, posterior view; 35 - posterior end, lateral view; 36 - posterior end, ventral view.

Wing. Tegula and basicosta yellow; costal spine not developed; base of vein $\mathrm{r}_{4+5}$ with 1-2 setulae dorsally and ventrally; cell $\mathrm{R}_{4+5}$ broadly open. A broad, dark brown, subapical band with distal margin from the junction 

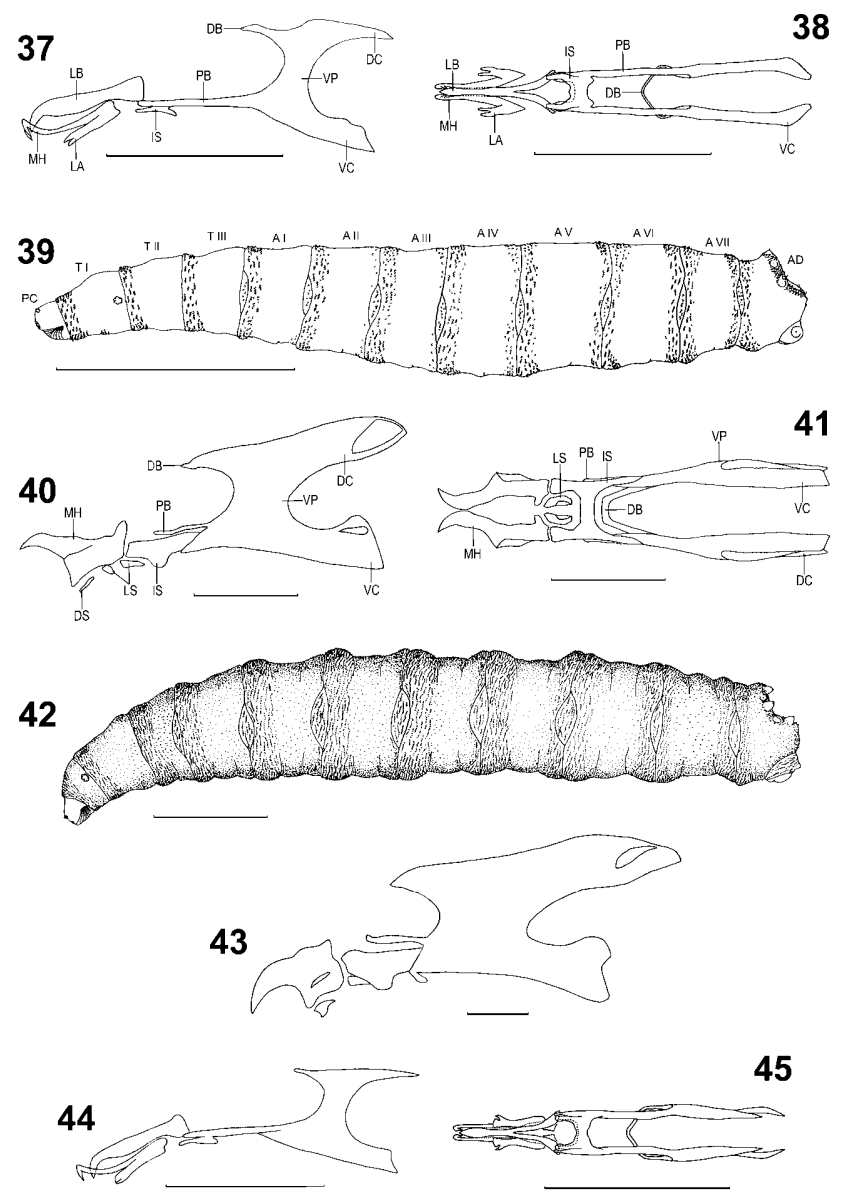

Figs 37-45. First, second and third instar larvae of Beludzhia phylloteliptera, first instar larva of Dolichotachina marginella: 37 - B. phylloteliptera, first instar, cephaloskeleton, lateral view; $38-B$. phylloteliptera, first instar, cephaloskeleton, ventral view; $39-B$. phylloteliptera, second instar, habitus, lateral view; $40-B$. phylloteliptera, second instar, cephaloskeleton, lateral view; $41-B$. phylloteliptera, second instar, cephaloskeleton, ventral view; $42-B$. phylloteliptera third instar, habitus, lateral view; $43-B$. phylloteliptera, third instar, cephaloskeleton, lateral view; $44-D$. marginella, first instar, cephaloskeleton, lateral view; $45-D$. marginella, first instar, cephaloskeleton, ventral view. Scales $0.1 \mathrm{~mm}$ (Figs 37, 38, 40, 41, 43-45) and $1 \mathrm{~mm}$ (Figs 39, 42). Abbreviations: AI-AVII abdominal segments, AD - anal division, DB - dorsal bridge, DC - dorsal cornua, DS - dental sclerite, IS - intermediate sclerite, LA - lateral arm, LB - labrum, LS - labial sclerite, MH - mouthhook, PB - parastomal bar, PC - pseudocephalon, TI-TIII - thoracic segments, VC - ventral cornua, VP - vertical plate.

between $r_{2+3}$ and costa to the bend of vein $\mathrm{m}$; a narrower and fainter apical band running from tip of vein $r_{4+5}$ and divided into two almost separate areas by vein $\mathrm{m}$.

Abdomen. Integument generally black, but with lighter and sometimes faintly yellowish colour on antero-lateral parts. T1+2 black, without microtrichosity; T3-T4 with more or less drop-shaped median black spot and square lateral black spots; T5 with silvery grey microtrichosity in about anterior half; terminalia shining black, without microtrichosity.
Terminalia (Figs 86-87). Cercus with scattered bristles and short, clothing setae in basal two thirds, almost bare distally; gently curved and gradually tapering into a moderately pointed tip. Surstylus with clothing setae restricted to the upper part of the base near the articulation with epandrium and cercus; with scattered bristles along the broad, middle part, practically bare along anterior margin and at tip; straight, almost as long as cercus, evenly rounded apically. Pregonite with a broad base, curving abruptly into an anteriorly-directed and slightly twisted tip; postgonite elongate, with a strong bristle situated near base on a distinct protuberance, with the broadest part just before tip. Phallus with weakly differentiated ventral plate, dorsal plate bifid apically, membranous part of distiphallus with numerous denticles.

Female (Figs 81, 83). Differs from the male in the following features: Scape and pedicel light brown, flagellomere 1 dark brown. Flagellomere 1 slightly shorter than arista, aristomere 2 twice as long as distal diameter, aristomere 3 thickened in basal half, frons moderately protruding, wings entirely hyaline, foretarsus without hair-like setae. Abdominal integument entirely black, and lateral abdominal spots well-defined.

First instar larva (Figs 1-15, 37, 38, 54-56)

Integument covered by longitudinal cuticular ridges (Figs 5, 8-10, 54, 56). Each of the pseudocephalic lobes with an antennal peg situated in a distinct socket on the dorsal surface (Figs 1, 2, 5, 56). Integument behind the antenna wrinkled by short, longitudinal ridges (Figs 1, 5). Maxillary palpus located on the anterior surface of the pseudocephalic lobe and shaped as a flattened protuberance (Figs 1,2). Central part of maxillary palpus with a cluster of six distinct sensilla, three set in swollen sockets and three without sockets (Fig. 4). The dorso-median sensillum basiconicum (sbl as explained above) is distinctly elongated and with a slightly swollen, almost spherical tip; the lateral sensillum basiconicum (sb3) is flattened and scale- or ear-like; and the three sensilla coeloconica with very distinct sockets of about equal size. Two additional sensilla coeloconica (ns1, ns2, "separated sensilla" sensu Szpila \& Pape 2005a, b) arranged at the dorsal periphery of the maxillary palpus. Ventral organ above and laterally to the functional mouth opening, shaped as a flat, fleshy lobe (Figs 1, 2, 5, 7). Pseudocephalon laterally with broad, flat cheek organ bearing central sensilla (Figs $1,2,5,6)$. Oral ridges originating from lower part of functional mouth opening and running at an acute angle towards the lateral parts of pseudocephalon (Figs 1-3, 5). Oral ridges limited laterally and posteriorly by the cheek organ.

Cephaloskeleton consisting of an unpaired labrum, paired mouthhooks, an unpaired intermediate sclerite, dorsal bridge, paired parastomal bars, and paired vertical plates each with ventral and dorsal cornua (Figs 37, 38, $55,56)$. Labrum strongly sclerotised and pointed. Basal part of labrum articulates with anterior part of parastomal bars. Apical part of labrum shaped as a downward-curved, pointed hook. Mouthhooks moderately sclerotised and equipped with a lateral, arm-like extension at 


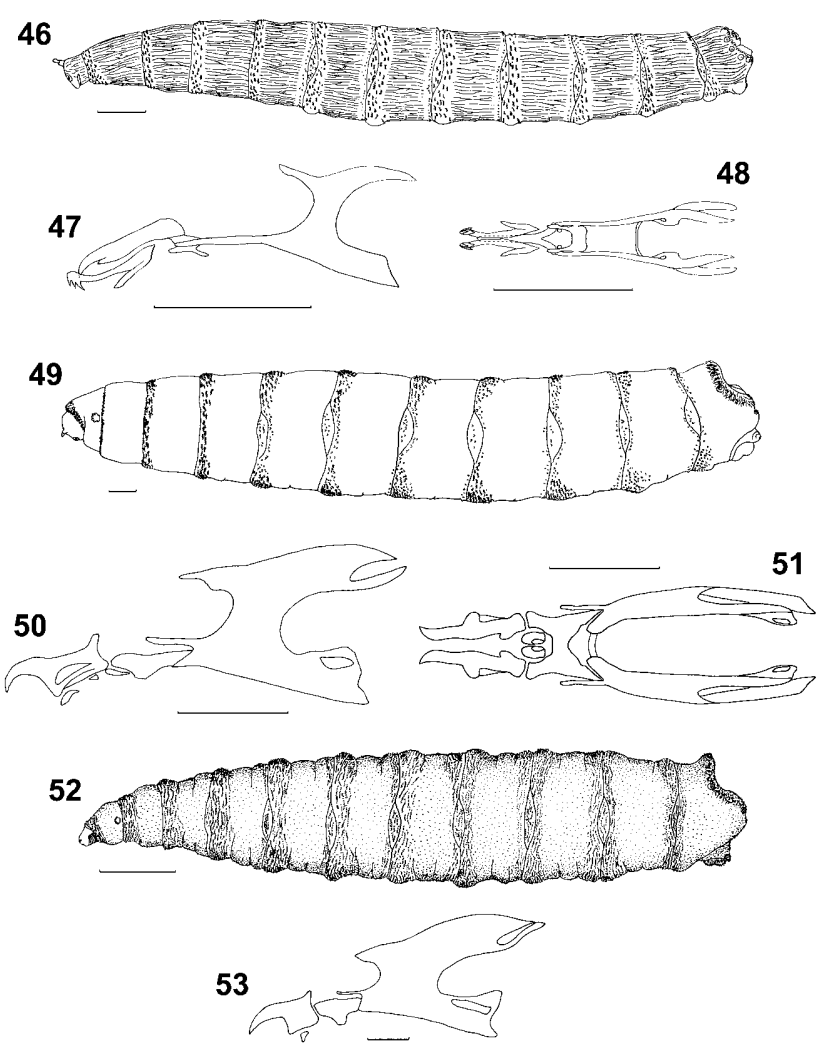

Figs 46-53. First, second and third instar larvae of Phylloteles pictipennis: 46 - first instar, habitus, lateral view; 47 - first instar, cephaloskeleton, lateral view; 48 - first instar, cephaloskeleton, ventral view; 49 - second instar, habitus, lateral view; 50 -second instar, cephaloskeleton, lateral view; 51 -second instar, cephaloskeleton, ventral view; 52 - third instar, habitus, lateral view; 53 -third instar, cephaloskeleton, lateral view. Scales $0.1 \mathrm{~mm}$ (Figs 46-51, 53) and $1 \mathrm{~mm}$ (Fig. 52).

the base (Figs 37, 38). Apical part of each mouthhook equipped with a few teeth (Fig. 3). The weakly sclerotised intermediate sclerite located between and ventral to the parastomal bars (Fig. 38). Dorsal cornua narrower than the ventral cornua, and vertical plate similar in width to ventral cornua. Dorsal bridge narrow and weakly sclerotised but, still fully complete (Fig. 38).

Segments TI-TIII equipped with spinose bands anteriorly (Figs 5, 54), with remaining surface formed into numerous longitudinal, cuticular ridges. Spines individually separated from each other (Fig. 5) or sometimes a few fused basally (Fig. 2). Paired Keilin's organs and two pairs of lateral papillae on each of TI-TIII. Keilin's organs have the usual form of three trichoid sensilla situated in one pit.

Segments AI-AVII armed with both anterior and posterior spinose bands (Figs 8, 9, 54). Anterior bands with three to six rows of spines on all abdominal segments, with numbers of rows decreasing toward the posterior end of the body, especially laterally and dorsally. Posterior bands with a single row (sometimes doubled) of spines on dorsal and lateral surfaces of AI-AVII. Ventral number of rows of spines may reach three-to four. Laterally each of AI-AVII with distinct creeping welts covered by spines (Figs 9, 14). Ventrally each of AI-AVII and the anal division with one fleshy, unpaired proleg (Figs 9, 14, $15,54)$. Prolegs situated close to anterior border of each segment and without spines (Figs 11, 12). Each of segments AI-AVII equipped ventrally with a central transverse crevice (Figs 9,54) and both ventrally and dorsally with a few sensilla (Figs 8,9). Seven pairs of rather flat papillae (P1-P7) present on the anal division, with papillae P1, P3, P5 and P7 bearing an elongated apical sensillum (Figs 14-15). Crevice containing anal opening situated between the anal papillae (Fig. 15). Spiracular cavity absent. Spiracular field surrounded by a ring of hair-like spines (Fig. 13).

Second instar larva (Figs 39-41, 57-59, 62)

Surface of body covered by weak cuticular ridges which are invisible under light microscopy. Oral ridges are multiplicated (Fig. 59). Maxillary palpus like first instar but second sensillum basiconicum not elongated.

The mouthhooks are the most anterior sclerites of the cephaloskeleton (Figs 40, 41, 58, 59). Anterior part of each mouthhook is straight with a downward-curved pointed tip. Basal part of the mouthhook robust and with some lateral extension. Postero-dorsal angle or corner of the mouthhook is drawn out into a distinct process (Figs 40, 58). Dental and labial sclerites below each mouthhook, both sets only partially sclerotised, with their exact shape difficult to define. Posterior part of labial sclerite situated between anterior arms of intermediate sclerite. Behind the intermediate sclerite, the tentoropharyngeal sclerite consists of paired parastomal bars, a complete dorsal bridge, vertical plates, and ventral and dorsal cornu (Figs 40-41). Parastomal bars extending far forward above the intermediate sclerite. Vertical plate wider than ventral and dorsal cornua. Both dorsal and ventral cornua with developed window (Fig. 40).

Anterior spiracle with four branches (Fig. 62). Segments TI-TIII with spinose bands only anteriorly (Figs 39, 57). Abdominal segments armed with both anterior and posterior spinose bands (Fig. 39). Spinulation difficult to observe because of weak sclerotisation of spines (Fig. 57). Segment AI with the posterior spine band equipped with only few spines, posterior spine bands of segments AII-AVII equipped with three-five rows of spines. Anterior spine bands with three to eight rows of spines on all abdominal segments, with decreasing numbers of rows toward the end of the body, especially laterally and dorsally. Distinct lateral creeping welts covered by spines between the abdominal segments (Fig. 39). Ventrally each of AI-AVII equipped with a transverse furrow.

Seven pairs of papillae (P1-P7) present on the anal division; P4 very poorly visible under the light microscope. Anal papillae developed as spherical structures (Fig. 39) lying latero-posteriorly to the anal opening. Spiracular cavity shallow and weakly developed. Spiracular field surrounded by a ring of hair-like spines (Fig. 39). 

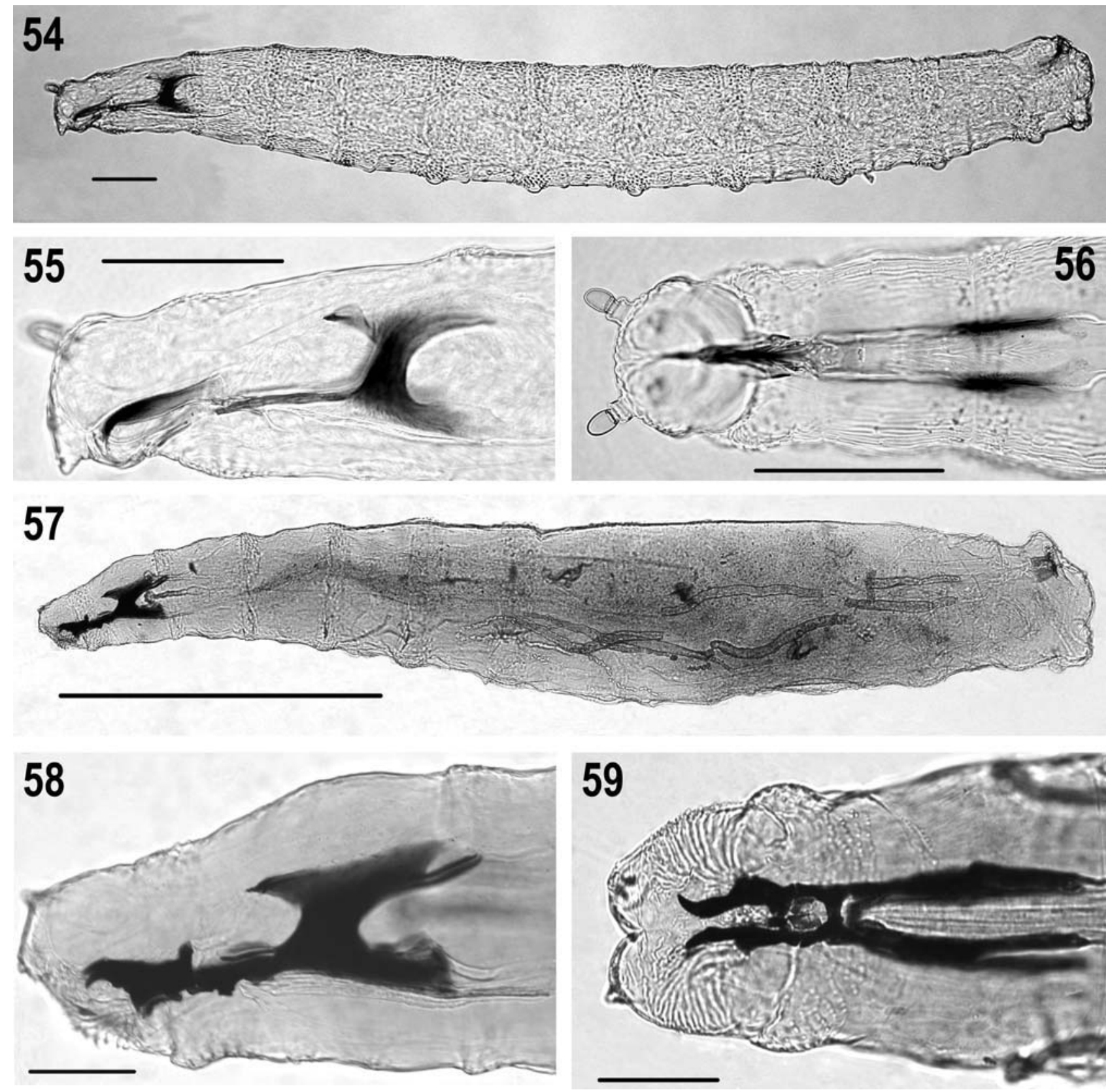

Figs 54-59. First and second instar larvae of Beludzhia phylloteliptera: 54 - first instar, habitus, lateral view; 55 - first instar, cephaloskeleton, lateral view; 56 - first instar, cephaloskeleton, ventral view; 57 - second instar, habitus, lateral view; 58 - second instar, cephaloskeleton, lateral view; $59-$ B. phylloteliptera, second instar, cephaloskeleton, ventral view. Scales $0.1 \mathrm{~mm}$ (Figs 54-56, 58, 59) and $1 \mathrm{~mm}$ (Fig. 57).

Third instar larva (Figs 42, 43, 60, 61, 63-65)

Integument equipped with small spherical warts (Fig. 64). Numerous oral ridges cover the ventral sides of both pseudocephalic lobes. Cephaloskeleton more robust than in the second instar but with the same general shape (Figs 43, 60). Apical part of each mouthhook shaped as a down-curved, pointed hook. Dental and labial sclerites below the massive basal part of the mouthhooks. Posterior part of the labial sclerites between the anterior arms of the intermediate sclerite. Parastomal bars go far forward above the intermediate sclerite. Dorsal bridge welldeveloped. Width of vertical plates is greater than the width of ventral and dorsal cornua. Dorsal cornua with a distinctly visible window. Posterior part of dorsal cornu closing the window weakly sclerotised.

Anterior spiracles with four branches (Fig. 63). Segments TI-TIII equipped with spinose bands only anteriorly (Fig. 42). Spines small and weakly sclerotised (Fig. 65). Spinose bands composed of five-eight rows of spines on AI-AVI, six-seven rows on AVII. Anterior spinose bands are strong on all abdominal segments. Posterior spinose bands becoming stronger towards the posterior part of body. Distinct creeping welts covered by rows of spines between abdominal segments (Fig. 42).

All seven pairs of papillae (P1-P7) present on the anal division. Anal papillae developed as spherical structures 

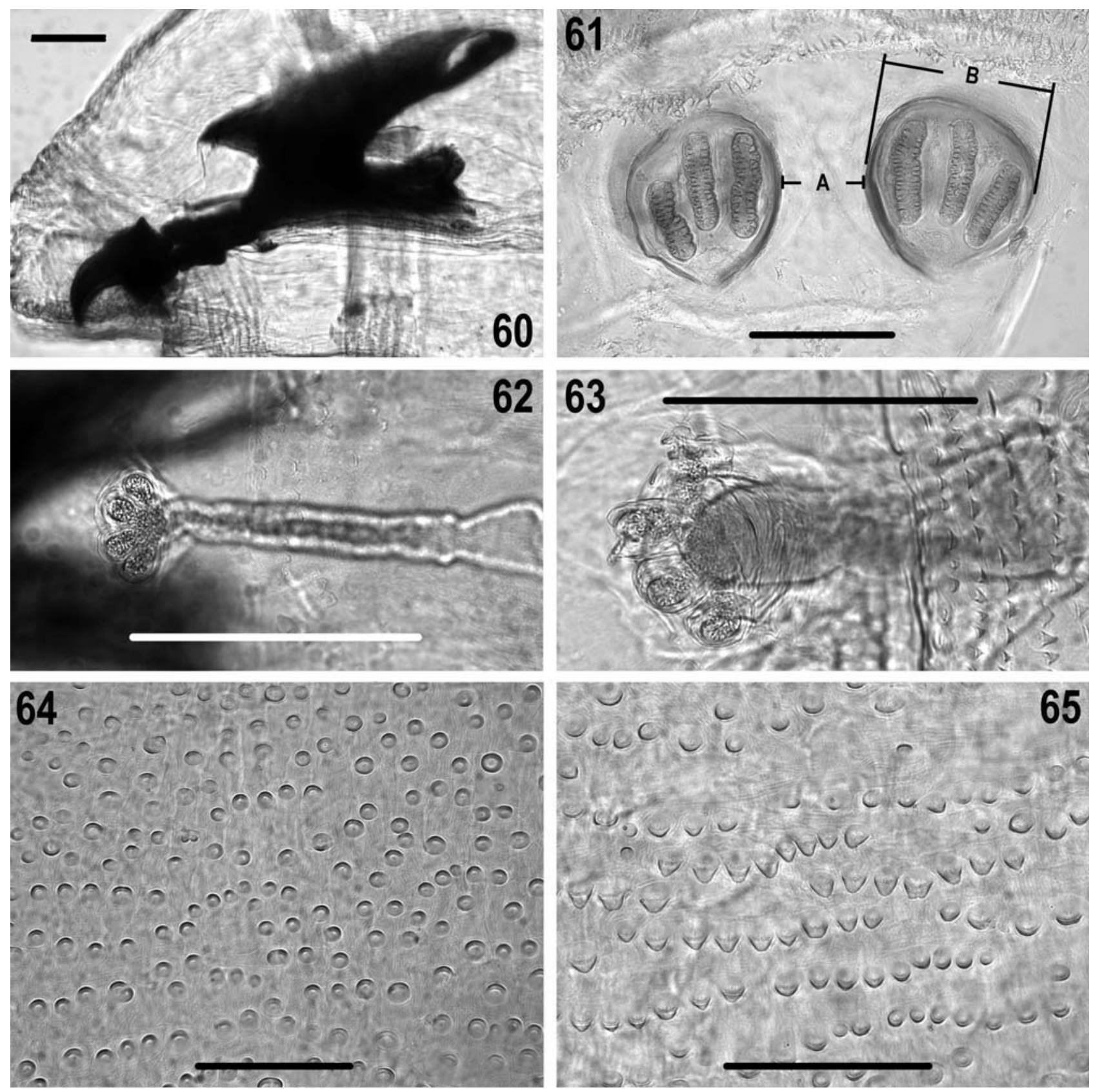

Figs 60-65. Third and second instar larvae of Beludzhia phylloteliptera: 60 - third instar, cephaloskeleton, lateral view; 61 - third instar, posterior spiracles; 62 - second instar, anterior spiracles; 63 - third instar, anterior spiracles; 64 - third instar, integumental warts; 65 - third instar, spines, anterior spinose band A II. Scales $0.1 \mathrm{~mm}$.

(Fig. 42) postero-laterally to anal opening. Spiracular cavity shallow and weakly developed (posterior spiracles distinctly visible). Spiracular distance factor 0.51 . Slits of spiracles straight and peritreme interrupted close to ecdysial scar (Fig. 61). Spiracular field surrounded by a ring of hair-like spines (Fig. 42).

\section{Dolichotachina marginella (Wiedemann, 1830)}

Description of adults, see Rohdendorf (1935), Séguy (1941). Fig. 84.

First instar larva (Figs 16-22, 44, 45, 66-68)

General morphology resembles that of B. phylloteliptera. Most important differences are the generally more robust body shape (Fig. 66), socket of maxillary palpus much larger (Figs 16, 17, 68), apical part of mouthhooks tapering into a single tooth (Figs 17, 44, 45), and anal papillae lying posteriorly to the crevice containing the anal opening (Fig. 22).

\section{Phylloteles pictipennis Loew, 1844}

Description of adults, see Séguy (1941), Zumpt (1973), Rohdendorf (1975), Pape (1987a,b), Povolný \& Verves (1997). Fig. 85.

First instar larva (Figs 23-36, 46-48, 69-71)

General morphology resembles that of B. phylloteliptera. Most important differences are a more robust gen- 

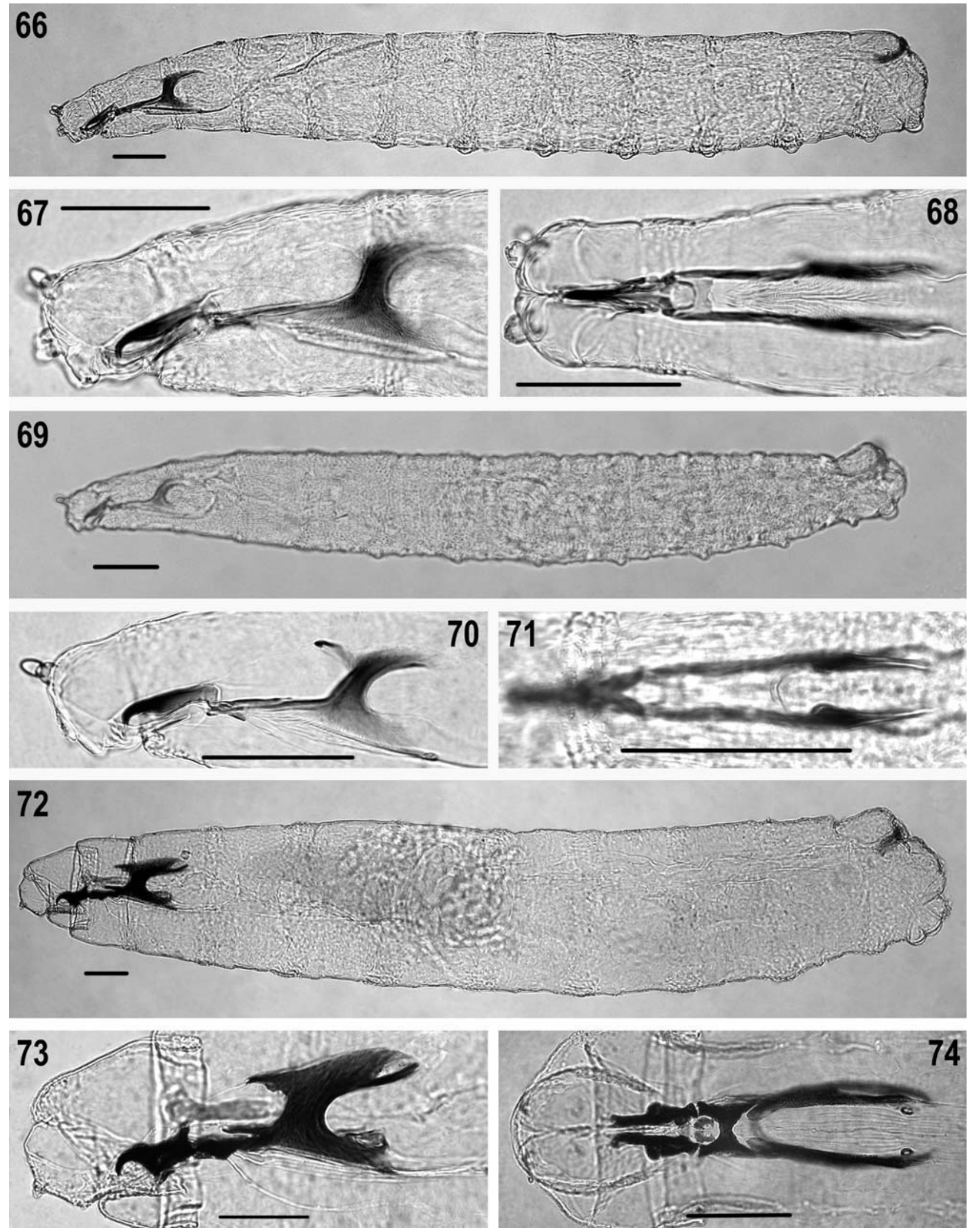

Figs 66-74. First instar larva of Dolichotachina marginella, first and second instar larvae of Phylloteles pictipennis: 66 - D. marginella, first instar, habitus, lateral view; $67-$ D. marginella, first instar, cephaloskeleton, lateral view; 68 - D. marginella, first instar, cephaloskeleton, lateral view; 69 - P. pictipennis, first instar, habitus, lateral view; $70-P$. pictipennis, first instar, cephaloskeleton, lateral view; $71-P$. pictipennis, first instar, cephaloskeleton, ventral view; $72-P$. pictipennis, second instar, habitus, lateral view; $73-$ P. pictipennis, second instar, cephaloskeleton, lateral view; $74-P$. pictipennis, second instar, cephaloskeleton, ventral view. Scales $0.1 \mathrm{~mm}$. 

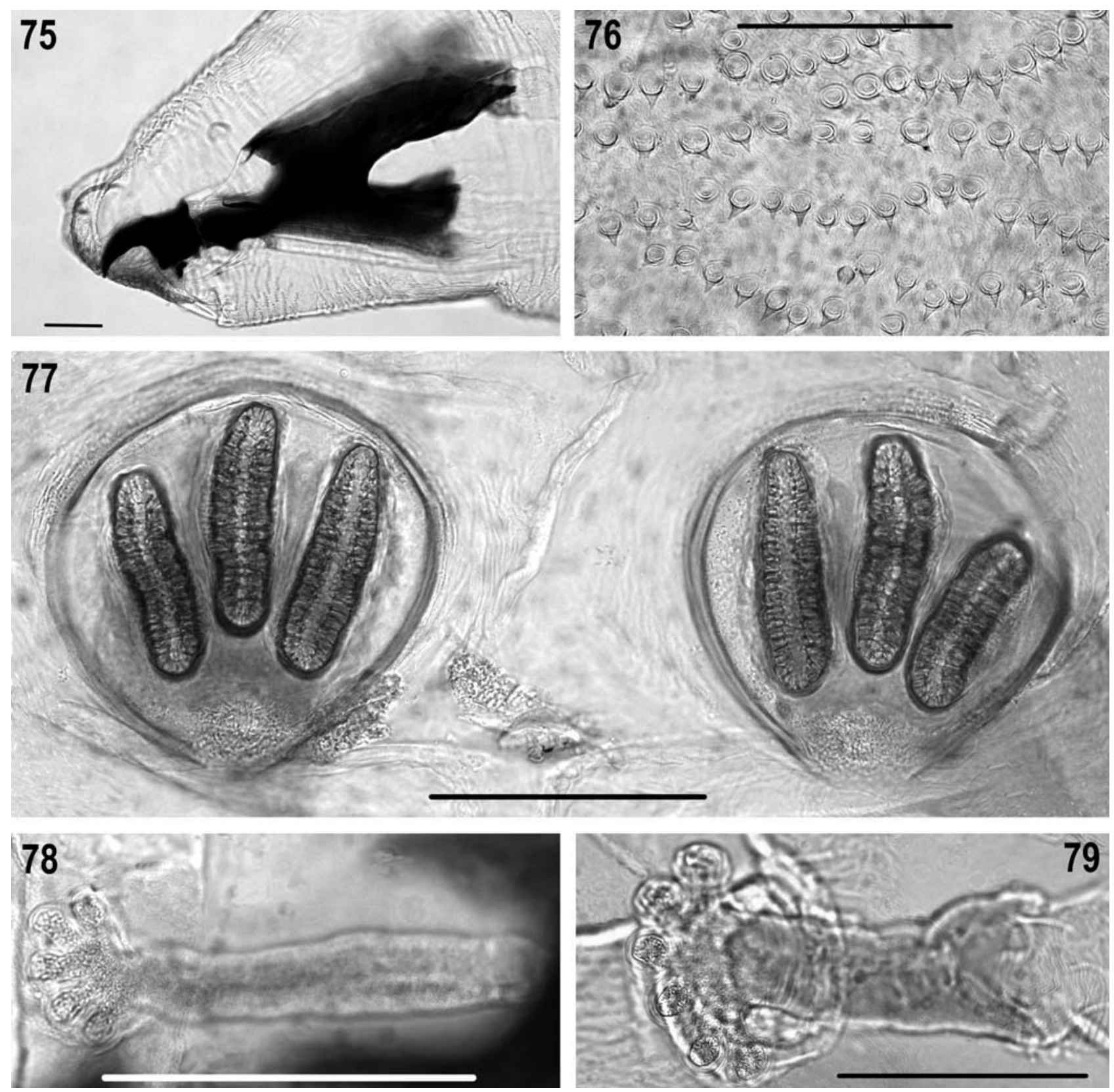

Figs 75-79. Third and second instar larvae of Phylloteles pictipennis: 75 - third instar, cephaloskeleton, lateral view; 76 - third instar, spines, anterior spinose band A II; 77 - third instar, posterior spiracles; 78 - second instar, anterior spiracles; 79 - third instar, anterior spiracles. Scales $0.1 \mathrm{~mm}$.

eral body shape (Fig. 69) and the anal papillae lying posteriorly to the crevice containing the anal opening (Figs $35,36)$.

Second instar larva (Figs 49-51, 72-74, 78)

General morphology resembles that of B. phylloteliptera. Most important differences are the arch-like curved anterior part of mouthhooks (Figs 50, 73), anterior spiracle with five branches (Fig. 78), the posterior spine bands with a single (sometimes double) row of spines on dorsal and lateral surfaces of AII-AVII (Fig. 49).

Third instar larva (Figs 52, 53, 75-77, 79)

General morphology resembles that of B. phylloteliptera. Most important differences are the sharp tips of the integumental warts (resembling spines) (Fig. 76), window in ventral cornu present (Fig. 53, 75), anterior spiracle with five to six branches (Fig. 79), posterior spiracles slightly more separated (SDF $=0.61)$ (Fig. 77).

\section{Comparative larval morphology}

In comparison with Metopia spp., which show significant differences in the first instar larvae between species with almost identical adults (Szpila \& Pape, 2005b), the first instar larvae of Beludzhia, Dolichotachina and Phylloteles show a remarkably high level of morphological similarity. Also in light of the often striking morphological differences between first instar Miltogramminae as compared to the extensive homogeneity of saprophagous oestroid larvae, the extensive similarity between 

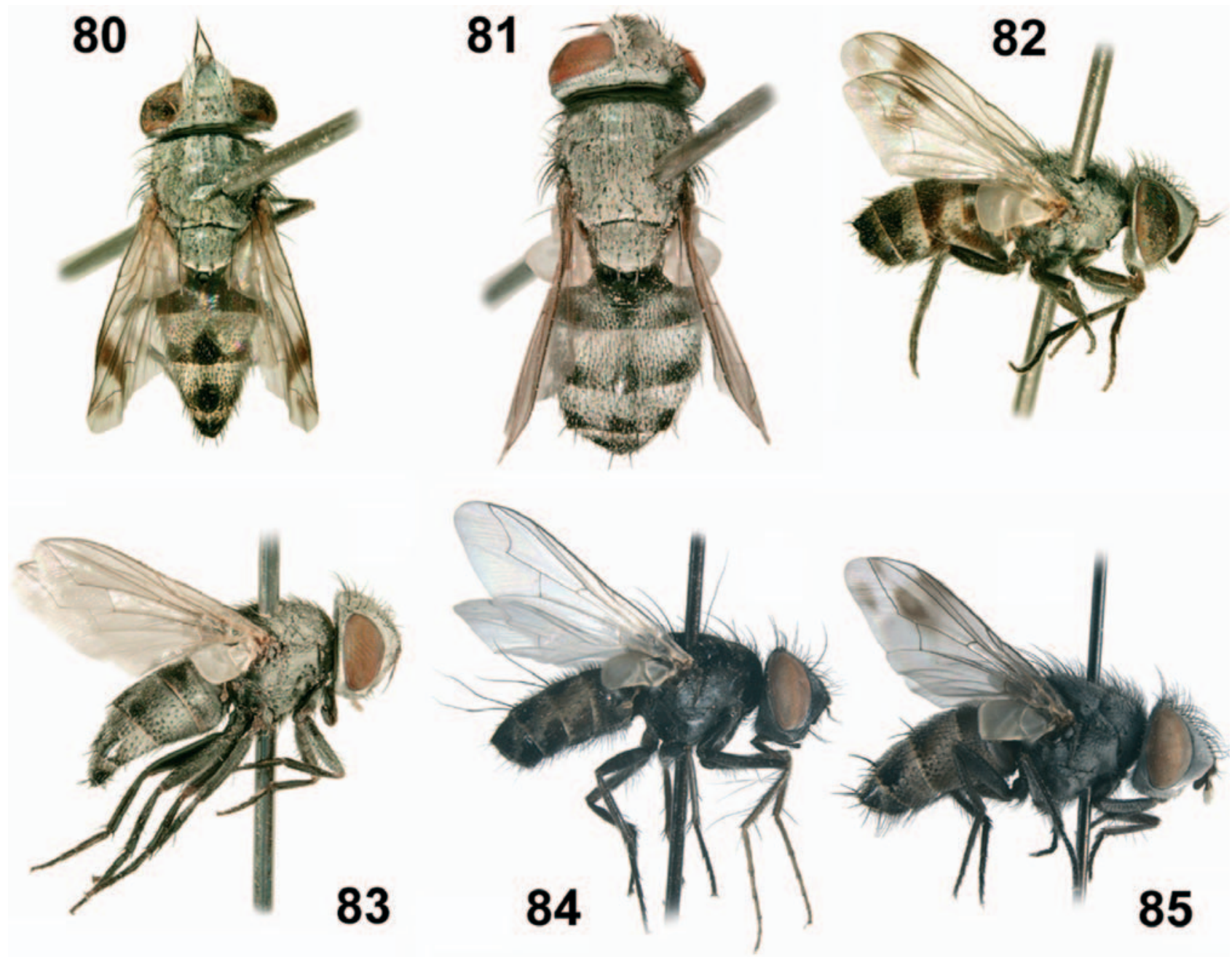

Figs 80-85. Adults of species of Phyllotelini: 80 - Beludzhia phylloteliptera, male, dorsal view; 81 - B. phylloteliptera, female, dorsal view; $82-B$. phylloteliptera, male, lateral view; $83-B$. phylloteliptera, female, lateral view; 84 - Dolichotachina marginella, male, lateral view; 85 - Phylloteles pictipennis, male, lateral view.

maggots of Beludzhia, Dolichotachina and Phylloteles is surprising. The first instar larva of $D$. marginella is distinguished from that of the other two species by the unique position of the maxillary palpus on a very large socket, the simple (i.e., unserrated) tip of the mouthhooks, and the more robust body shape. The maxillary palpus of $B$. phylloteliptera and $P$. pictipennis is level with the pseudocephalic surface, the mouthhooks are serrated at the tip, and the general body shape is more slender. Beside the body shape, the larva of $B$. phylloteliptera has the anal papillae situated lateral to the anal opening and is thus similar to Metopia spp. and Apodacra pulchra Egger 1861, whereas the anal papillae in the first instar of $D$. marginella and $P$. pictipennis are located behind the anal opening. In the second instar, the posterior spine bands of $P$. pictipennis have a single (rarely double) row of spines on the dorsal and lateral surfaces of segments AI-AVII, while $B$. phylloteliptera shows three-five rows of spines on segments AII-AVII.

Shared features of the first instar larvae of B. phylloteliptera, D. marginella and P. pictipennis that are particularly interesting in a phylogenetic context are:
(1) antennal peg much longer than diameter of maxillary palpus and with distinct socket;

(2) first sensillum basiconicum of maxillary palpus elongated;

(3) ventral organ on flat fleshy lobe;

(4) oral ridges present;

(5) mouthhook slender;

(6) mouthhook with lateral, arm-like projection;

(7) parastomal bar long and slender;

(8) cephaloskeleton with complete dorsal bridge;

(9) labrum with narrow anterior part clearly set off from wider basic part;

(10) pseudocephalon with large cheek-organ;

(11) integument with cuticular ridges;

(12) anterior proleg present;

(13) hair-like spines present around spiracular field;

(14) spiracular cavity absent.

Compared with the first instar of Apodacra pulchra and species of Metopia Meigen 1803 (Szpila \& Pape, 2005a, b), the first instar of Beludzhia, Dolichotachina and Phylloteles share several features otherwise found in generally saprophagous taxa, like the calliphorid subfamilies Calli- 

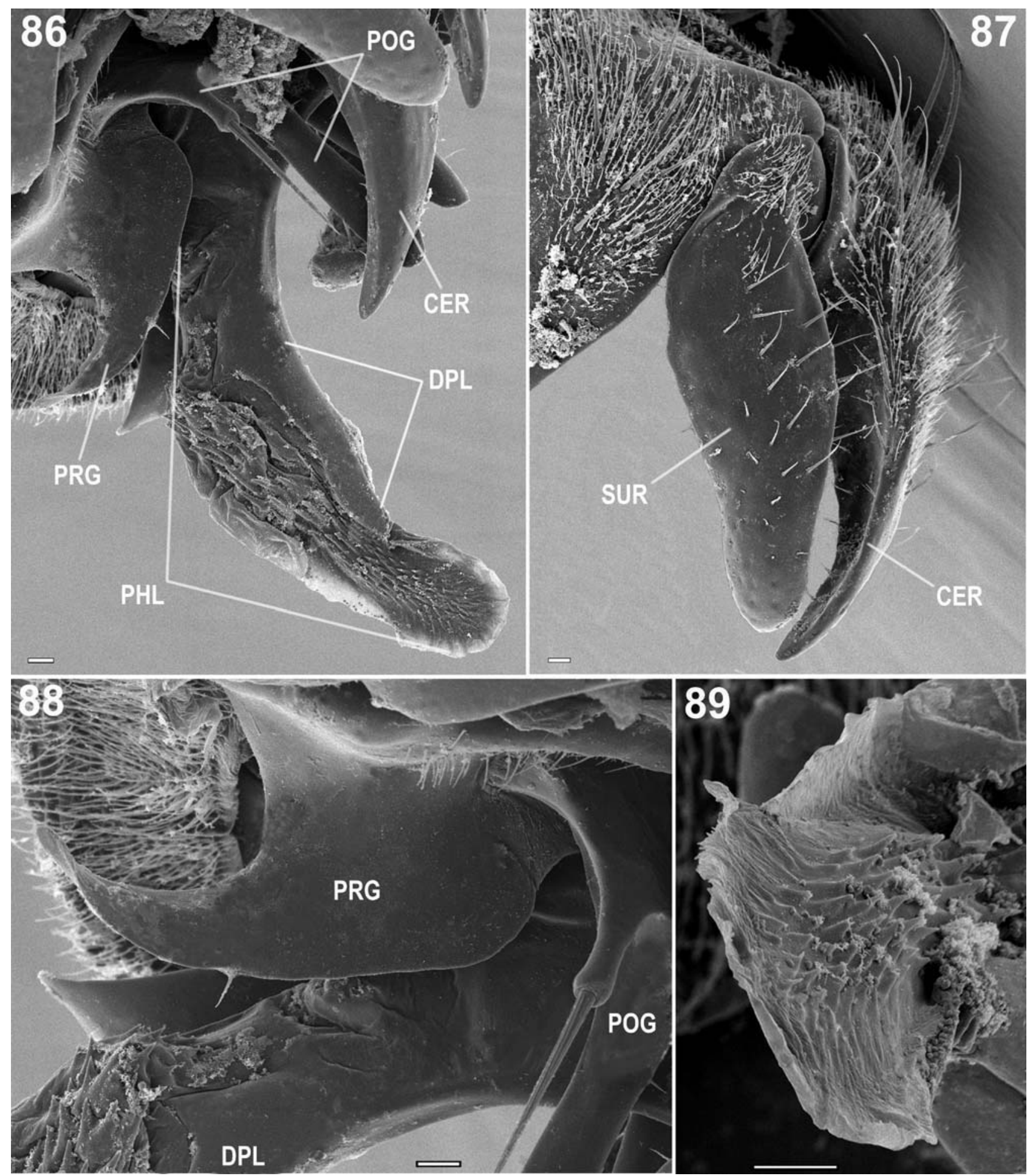

Figs 86-89. Male terminalia of Beludzhia phylloteliptera. 86 - phallus, lateral view; 87 - left surstylus and cercus, lateral view; 88 - left pre- and postgonite (in part), lateral view; 89 - tip of phallus, oblique distal view. Abbreviations: CER - cercus, DPL - dorsal plate of distiphallus, PHL - phallus, POG - postgonite, PRG - pregonite, SUR - surstylus. Scales $10 \mu \mathrm{m}$.

phorinae, Chrysomyinae, and Luciliinae (features 4, 7, 8, $13,14)$, or the remaining sarcophagid subfamilies Paramacronychiinae and Sarcophaginae (features 4, 8,13). Because of their widespread occurrence in the saprophagous Oestroidea, these features have been considered to be plesiomorphic (e.g., Lopes, 1983; also implicit in Zumpt, 1965; Rohdendorf, 1967; Erzinçlioğlu, 1989).
The elongated first sensillum basiconicum of the maxillary palpus and the cuticular ridges (features 2,11) were proposed as possible ground plan autapomorphies for the entire subfamily Miltogramminae by Szpila \& Pape (2005a). Neither of these two features have been observed in the first instar of any other member of the Oestroidea, but their presence in miltogrammine genera 
TABLE 1. Distribution of the most widely used diagnostic features from third instar Miltogramminae.

\begin{tabular}{|c|c|c|c|}
\hline & $\begin{array}{l}\text { Windows in dorsal } \\
\text { and ventral cornu }\end{array}$ & $\begin{array}{l}\text { Anterior spiracle - } \\
\text { number of branches }\end{array}$ & $\begin{array}{l}\text { SDF (spiracular distance } \\
\text { factor, see Fig. 61) }\end{array}$ \\
\hline $\begin{array}{l}\text { Amobia signata (Thompson, 1921; Plate XVI Fig. 115, Figs } \\
\text { XLb, XXXIXa) }\end{array}$ & absent & 6 & 1.06 \\
\hline Craticulina tabaniformis (Cuthbertson, 1939, Figs 2b,c) & present in both & 6 & 0.98 \\
\hline Eumacronychia nigricornis (Mullen et al., 1984, Figs 1-4) & present in both & $5-6$ & 0.15 \\
\hline $\begin{array}{l}\text { Euphyto nomiivora (Moradeshaghi \& Bohart, 1968, Figs } \\
\text { 11-13) }\end{array}$ & absent & $5-6$ & 0.72 \\
\hline $\begin{array}{l}\text { Metopia "leucocephala"; argyrocephala group } \\
\text { (Séguy, 1941, Fig. 412) }\end{array}$ & present in both & - & - \\
\hline $\begin{array}{l}\text { Miltogramma punctata (Thompson, 1921; Plate IX Fig. 21; } \\
\text { Plate XI Figs 46,49; Plate XII Fig. 59) }\end{array}$ & present in both & $6-7$ & 0.47 \\
\hline Senotainia albifrons (Verves, 1990; Fig. 211-213) & absent & $?$ & 1.57 \\
\hline $\begin{array}{l}\text { Senotainia conica (Thompson, 1921; Plate XVI Fig. 113, } \\
\text { Fig. XXXIIa, b) }\end{array}$ & only in dorsal cornu & 5 & 1.31 \\
\hline Senotainia tricuspis (Ferrar, 1987; Figs 75.120, 75.135) & absent & 5 & \\
\hline Beludzhia phylloteliptera & only in dorsal cornu & 4 & 0.51 \\
\hline Phylloteles pictipennis & present in both & $5-6$ & 0.61 \\
\hline
\end{tabular}

suspected to be phylogenetically close to the base (i.e., Macronychia Rondani, 1859; Eumacronychia Townsend, 1892; Xiphidiella Villeneuve, 1952; Chivamya Pape, 1996; Chorezmomyia Rohdendorf, 1935) needs to be confirmed before their status as subfamilial autapomorphies can be accepted.

The occurrence of oral ridges (feature 4 ) and the presence of hair-like spines around the posterior spiracular field (feature 13) are particularly interesting as these features are here reported for the first time in the subfamily Miltogramminae. Incidentally, the strongly modified oral ridges of Apodacra pulchra were not recognized as such by Szpila \& Pape (2005a), but what we described then as an enlarged, slit-like functional mouth opening is here reinterpreted as being formed by modified and enlarged oral ridges.

The arm-like projection or ridge on the basal part of the mouthhook (feature 6) is a feature shared with species of Metopia and not known from other miltogrammine taxa. The slender mouthhooks, the cheek organ, and the presence of an anterior segmental proleg (features 5, 10, 12) are unique character states that so far are shared exclusively by $B$. phylloteliptera, D. marginella and $P$. pictipennis.

A comparative discussion of the morphology of the second and third instar larva is restricted by the low number of species for which the morphology of these instars is known, and the general lack of details. Apart from $B$. phylloteliptera and $P$. pictipennis documented in the present paper, the second instar has only been documented for two additional species: Senotainia tricuspis (Meigen, 1838) and Craticulina tabaniformis (Fabricius, 1805) (for references, see Table 1). The situation is somewhat better for the third instar, where figures and descriptions are available in the literature for nine species: Amobia signata (Meigen, 1824); Craticulina tabaniformis; Eumacronychia nigricornis Allen, 1926; Euphyto nomiivora (James, 1955), Metopia sp.; Miltogramma punctata Meigen, 1824; Senotainia albifrons (Rondani, 1859); S. conica (Fallén, 1810) and S. tricuspis (Meigen, 1838) (for references, see Table 1). Cuticular structures and spinulation are only sufficiently figured and described for Miltogramma punctata and partly for Eumacronychia nigricornis. Cuticular structures of $M$. punctata figured by Thompson (1921, Plate XVIII, Fig. 151) resemble those observed for $B$. phylloteliptera and $P$. pictipennis (Figs 42, 52). Creeping welts on the ventral surface, as in B. phylloteliptera, are less prominent in $M$. punctata (Thompson, 1921: Plate VI, Fig. 2). General body shape and arrangement of spines of the third instar $E$. nigricornis (Mullen et al., 1984) are very similar to $B$. phylloteliptera and $P$. pictipennis. Spines are arranged in many rows, creating wide spinose bands that also cover the lateral creeping welts. The main difference concerns the shape of spines, which are uniquely multi-cuspoid in E. nigricornis.

Together with the shape of the mouthhook and labrum, the most widely used diagnostic features of the second and third instars are the occurrence of windows in the ventral and dorsal cornua of the cephaloskeleton and the number of branches of the anterior spiracle (Table 1). The latter varies from four to seven in the Miltogramminae and is low in comparison to other Sarcophagidae (Ferrar, 1987). With only four branches, the number observed in B. phylloteliptera is the lowest within the subfamily. Values of the spiracular distance factor (SDF) for all Miltogramminae mentioned here ranges from 0.15 (spiracles very close to each other) to 1.57. Values of SDF for $B$. phylloteliptera and $P$. pictipennis $(0.51$ and 0.61 , respectively) are in the middle of the range (Table 1). Posterior spiracles of $A$. signata, S. conica and M. punctata (see figures in Thompson 1921) differ from those described for B. phylloteliptera, P. pictipennis and E. nigricornis by shorter spiracular slits and a more spindle-like shape of the ecdysial scar. 
Generally, the second and third instars of B. phylloteliptera and $P$. pictipennis resemble larvae of other Sarcophagidae and Calliphoridae and they lack the unique morphological modifications of the first instar. One feature worthy of mention, however, is the occurrence of integumental warts (Figs 64, 76). A similar cuticular sculpturing has not been reported from any other member of the Sarcophagidae and has been reported from the Oestroidea for the third instar larvae of following genera of blowflies: Calliphora Robineau-Desvoidy, 1830 (Erzinçlioğlu, 1985; Liu \& Greenberg, 1989; Wallman, 2001), Chrysomya Robineau-Desvoidy, 1830 (Povolný, 2002; Sukontason et al., 2003), and Lucilia Robineau-Desvoidy, 1830 (Liu \& Greenberg, 1989).

\section{Phylogeny and classification}

While adult miltogrammine characters have proven reasonably informative for the circumscriptions of most genera, no tests of formal monophyly have been performed using modern matrix-based methods, and hypotheses of miltogrammine phylogenetic relationships mainly exist as vague indications in revisionary taxonomic works (e.g., Rohdendorf, 1930, 1935, 1971, 1975; Pape 1987a, b) or as more explicit but "handmade" cladograms with insufficient information on character state distributions (Rohdendorf, 1967; Verves, 1989). Only Pape (2006) presents an explicit analytical framework, although with a narrow taxon sampling and a low number of characters. Rohdendorf (1935) originally noted the similarity in colour pattern of wings and abdomen between Beludzhia phylloteliptera and Phylloteles pictipennis, but due to the long first flagellomere in the male $B$. phylloteliptera, he assigned this species to the subtribe Metopiina, together with the genera Metopia, Phrosinella Robineau-Desvoidy, 1863, Sphenometopa Townsend, 1908, Taxigramma Perris, 1852, Mesomelena Rondani, 1859 and Oebalia Robineau-Desvoidy, 1863. Rohdendorf later specifically suggested a sister group relationship between Oebalia and Beludzhia as the basal clade of his Metopiina (Rohdendorf, 1967, his Fig. 31), although cautioning that the high number of plesiomorphic features made this phylogenetic assignment tentative (p. 67). Verves (1989) suggested that a monotypic subtribe Beludzhiina would be the sister group of Apodacrina [Apodacra sensu Pape (1996)]. None of these authors, however, gave any arguments for their groupings. Male terminalia are used extensively in the classification of Sarcophagidae (e.g., Roback, 1954; Rohdendorf, 1967; Pape, 1994), but mostly for the subfamily Sarcophaginae and only to a very limited extent for the subfamily Miltogramminae (c.f., Verves, 1989; Pape, 2006). Clearly, the known features of adult morphology provide only sparse and conflicting evidence for the phylogenetic affinities of $B$. phylloteliptera. In contrast to this, the morphology of the first instar larva seems to carry evidence that Beludzhia is part of a clade also containing Dolichotachina and Phylloteles, but not including any of the remaining miltogrammine genera for which larval morphology is sufficiently known. The evidence in support of this is the shared presence of slender mouthhooks, the cheek organ, and the anterior segmental proleg, which are features so far not recorded from any other member of the Miltogramminae. Both Dolichotachina and Phylloteles have been considered - on adult morphology only - as members of a tribe Phyllotelini, which also contains Africasiomyia Rohdendorf, 1975, Hoplacephala Macquart, 1846, Hoplatainia Zumpt, 1961, Lamprometopia Macquart, 1846, Medomyia Rohdendorf, 1926, Sphecapatoclea Villeneuve, 1909 and Sphecapatodes Villeneuve, 1912 (Rohdendorf, 1975; Verves, 1989; Pape, 2006). Noditermitomyia Séguy, 1953 probably also belongs here, possibly as a synonym of Lamprometopia (Verves, 1988). Verves (1989) included Metopodia Brauer \& Bergenstamm, 1891 and Metopodiella Zumpt, 1961 in the Phyllotelini, but at least the former should be excluded as it shares several features with Taxigramma (Pape, 1996). We propose to include Beludzhia within the tribe Phyllotelini, although the postulated larval synapomorphies still have to be mapped more thoroughly before their exact level of synapomorphy can be settled.

Rearing experiments with $B$. phylloteliptera and P. pictipennis show broad feeding preferences for freshly killed insects (see Materials and Methods), but otherwise the Phyllotelini remains one of the biologically least investigated groups of miltogrammines. Hoplacephala is apparently associated with termites (Pape, 2006), at least some species of Dolichotachina and Phylloteles are breeding in locust egg pods (Greathead, 1963), Noditermitomyia arabops Séguy, 1953 is an internal parasitoid of termites (Séguy, 1953), and while Phylloteles pictipennis has been bred from a nest of the sphecid Philantus triangulum in Central Asia (Charykuliev \& Myartseva, 1964), a breeding record of this species from a sea turtle nest remains to be explained (McGowan et al., 2001). An association between Dolichotachina and ants has been suggested but remains speculative; Cuthbertson (1936, cited from Ferrar, 1987) observed females of D. cuthbertsoni entering nests and hovering above workers of the ant Plagiolepis Mayr, 1861, but with no actual breeding records. No information is available on the breeding biology of other genera of this tribe.

ACKNOWLEDGEMENTS. We want to express our most sincere thanks to T. van Harten, UAE Insect Project, Sharija, for hospitality and generous support during our field work in the United Arab Emirates. J. Wallman, School of Biological Sciences, University of Wollongong, NSW, kindly read and commented upon a draft of the manuscript, and J. Birkedal Schmidt, Zoological Museum, Copenhagen, helped with the habitus photographs. J. Faber and Z. Banach, Department of Histology \& Cytology, Zoology Institute of Jagiellonian University help us with taking excellent SEM pictures of $P$. pictipennis. The present work was supported by grants from the Polish Ministry of Science and Higher Education (grant no. 2 P04F 005 29) to KS and from the Danish Research Agency, Ministry of Science, Technology and Innovation to TP (grant no. 272-05-0431).

\section{REFERENCES}

Charykuliev D.M. \& Myartseva S.N. 1964: The natural enemies of Philantus triangulum. Kolkhoz. Sovkhoz. Proizv. Turk. [1964]: 84-88. 
Courtney G.W., Sinclair B.J. \& Meier R. 2000: Morphology and terminology of Diptera larvae. In Papp L. \& Darvas B. (eds): Contributions to a Manual of Palaearctic Diptera (with Special Reference to Flies of Economic Importance). Science Herald Press, Budapest, pp. 85-161.

Cuthbertson A. 1936: Biological notes on some Diptera in Southern Rodesia. Occ. Pap. Rhod. Mus. 4: 11-28.

Cuthbertson A. 1939: On the biology of Craticulina tabaniformis F., (Diptera: Sarcophagidae) which breeds in the nests of sand wasp Bembex F. (Sphecidae). J. Entomol. Soc. Sth. Afr. 1: 1-8.

Draber-Mońko A. 2004: Calliphoridae, Plujki (Insecta, Diptera). Fauna Poloniae 23. Natura Optima Dux Fundation \& MaZI PAS, Warsaw, 659 pp. [in Polish].

EMdEN F.I. van 1965: The Fauna of India and Adjacent Countries. Diptera 7, Muscidae Part 1. Delhi, 647 pp.

ERZINÇLIOĞLU Y.Z. 1985: Immature stages of British Calliphora and Cynomya, with re-evaluation of the taxonomic characters of larval Calliphoridae (Diptera). J. Nat. Hist. 19: 69-96.

ERZINÇLIOĞLU Y.Z. 1989: The origin of parasitism in blowflies. Br. J. Entomol. Nat. Hist. 2: 125-127.

FERRAR P. 1987: A guide to the breeding habits and immature stages of Diptera Cyclorrhapha. Entomonograph 8: 1-907.

GARM A. 2004: Revising the definition of the crustacean seta and setal classification systems based on examinations of the mouthpart setae of seven species of decapods. Zool. J. Linn. Soc. 142: 233-252.

GreatheAd D.J. 1963: A review of the insect enemies of Acridoidea (Orthoptera). Trans. R. Entomol. Soc. Lond. 114: 437-517.

Kristensen N. P. \& Simonsen T.J. 2003: 'Hairs' and scales. In Kristensen N.P. (ed.) Lepidoptera: Moths and Butterflies 2. Handbuch der Zoologie/Handbook of Zoology IV/36. Walter de Gruyter, Berlin \& New York, pp. 9-22.

Liu D. \& GreenBerg B. 1989: Immature stages of some flies of forensic importance. Ann. Entomol. Soc. Am. 82: 80-93.

LOPES H.S. 1983: The importance of the mandible and clypeal arch of the first instar larvae in the classification of the Sarcophagidae (Diptera). Revta Bras. Entomol. 26: 293-326.

McGowan A., Broderich A.C., Deeming J., Godley B.J. \& HanCOCK E.G. 2001: Dipteran infestation of loggerhead (Caretta caretta) and green (Chelonia mydas) sea turtle nests in northern Cyprus. J. Nat. Hist. 35: 573-581.

Merz B. \& HaENNI J.-P. 2000: Morphology and terminology of adult Diptera (other than terminalia). In Papp L. \& Darvas B. (eds): Contributions to a Manual of Palaearctic Diptera (with Special Reference to Flies of Economic Importance). Science Herald Press, Budapest, pp. 21-51.

Moradeshaghi M.J. \& Bohart G.E. 1968: The biology of Euphytomima nomiivora (Diptera: Sarcophagidae), a parasite of the alkali bee, Nomia melanderi (Hymenoptera: Halictidae). J. Kansas Entomol. Soc. 41: 456-473.

Mullen G.R., Trauth S.E. \& Sellers J.C. 1984: Association of a miltogrammine fly, Eumacronychia nigricornis Allen (Diptera: Sarcophagidae), with the brood burrows of Sceloporus undulatus (Latrielle) [sic!] (Reptilia: Lacertillia [sic!]). J. Georgia Entomol. Soc. 19: 1-6.

PAPE T. 1987a: The Sarcophagidae (Diptera) of Fennoscandia and Denmark. Fauna Entomol. Scand. 19: 1-203.

PAPE T. 1987b: Revision of Neotropical Metopia Meigen (Diptera: Sarcophagidae). Syst. Entomol. 12: 81-101.

PAPE T. 1994: The world Blaesoxipha Loew, 1861 (Diptera: Sarcophagidae). Entomol. Scand. (Suppl.) 45: 1-247.

PAPE T. 1996: Catalogue of the Sarcophagidae of the world (Insecta: Diptera). Mem. Entomol. Internat. 8: 1-558.
PAPE T. 2006: A new species of Hoplacephala with a discussion of generic monophyly (Diptera: Sarcophagidae). Zootaxa 1183: $57-68$.

PovolnÝ D. 2002: Chrysomya albiceps (Wiedemann, 1819): the first forensic case in Central Europe involving this blowfly (Diptera, Calliphoridae). Acta Univ. Agric. Silvic. Mendel. Brun. 50: 105-112.

Povolný D. \& Verves Yu.G. 1997: The flesh-flies of Central Europe (Insecta, Diptera, Sarcophagidae). Spixiana (Suppl.) 24: 1-260.

Roвack S.S. 1954: The evolution and taxonomy of the Sarcophaginae (Diptera, Sarcophagidae). Illinois Biol. Monogr. 23: $1-181$.

RoHDENDORF B.B. 1930: 64 h. Sarcophaginae. In Lindner E. (ed.): Die Fliegen der Palaearktischen Region 11 [Lieferung 39]. E. Schweizerbart'sche Verlagsbuchhandlung, Stuttgart, pp. 1-48.

ROHDENDORF B.B. 1935: 64 h. Sarcophaginae. In Lindner E. (ed.): Die Fliegen der Palaearktischen Region 11 [Lieferung 887. E. Schweizerbart'sche Verlagsbuchhandlung, Stuttgart, pp. 49-128.

RoHDENDORF B.B. 1967: The directions of historical development of Sarcophagidae (Diptera). Proc. Paleont. Inst. Akad. Sci. USSR 116: 1-92.

ROHDENDORF B.B. 1971: 64 h. Sarcophaginae. In Lindner E. (ed.): Die Fliegen der Palaearktischen Region 11 [Lieferung 285]. E. Schweizerbart'sche Verlagsbuchhandlung, Stuttgart, pp. 129-176.

RoHDENDORF B.B. 1975: 64 h. Sarcophaginae. In Lindner E. (ed.): Die Fliegen der Palaearktischen Region 11 [Lieferung 311]. E. Schweizerbart'sche Verlagsbuchhandlung, Stuttgart pp. 177-232

SÉGUY É. 1941: Études sur les mouches parasites. 2. Calliphorides, calliphorines (suite), sarcophagines et rhinophorides de l'Europe occidentale et méridionale. Encycl. Entomol. (Ser. A) 21: 1-436.

SÉGUY É. 1953: Diptères calliphorides inféodes au Noditermes curvatus en Côte d'Ivoire. Bul. Sect. Fr. Un. Int. Etud. Insectes Soc. 1: 21-28.

Spofford M.G., Kurczewski F.E. \& Downes W.L. JR. 1989: Nearctic species of Miltogrammini (Diptera: Sarcophagidae) associated with species of Aculeata (Hymenoptera: Vespoidea, Pompiloidea, Sphecoidea, Apoidea). J. Kansas Entomol. Soc. 62: 254-267.

Sukontason K.L., Sukontason K., Lertthamnonghtam S., Kuntalue B., Thijuk N., Vogtsberger R.C. \& Olson J.K. 2003: Surface ultrastructure of Chrysomya rufifacies (Macquart) larvae (Diptera: Caliphoridae). J. Med. Entomol. 40: 259-267.

SzPILA K. 2003: First instar larvae of nine West-Palaearctic species of Pollenia Robineau-Desvoidy, 1830 (Diptera, Calliphoridae). Entomol. Fenn. 14: 193-210.

SzPILA K. 2004: First instar larvae of five West Palaearctic species of Bellardia Robineau Desvoidy, 1863 and Onesia Robineau-Desvoidy, 1830 (Diptera, Calliphoridae). Stud. Dipterol. 11: 301-312.

SZPILA K. \& PAPE T. 2005a: The first instar larva of Apodacra pulchra (Diptera: Sarcophagidae, Miltogramminae). Insect Syst. Evol. 36: 293-300.

SzPILA K. \& PAPE T. 2005b: Comparative morphology of the first instar larva of three species of Metopia Meigen (Diptera: Sarcophagidae). Acta Zool. 86: 119-134.

THOMPson W.R. 1921: Recherches sur les diptères parasites. I Les larves des Sarcophagidae. Bull. Biol. Fr. Belge 54: 313-463. 
Verves Yu.G. 1988: The Sarcophagidae (Diptera) of the Lund University collection. Vestn. Zool. [1988]: 11-19 [in Russian, English abstr.].

Verves Yu.G. 1989: The phylogenetic systematics of the miltogrammatine flies (Diptera, Sarcophagidae) of the world. Japan J. Med. Sci. Biol. 42: 111-126.

Verves Yu.G. 1990: A key to Sarcophagidae (Diptera) of Mongolia, Siberia and neighbouring territories. Ins. Mongolia 11: 516-616.

Verves Yu.G. 1994: A key to genera and subgenera of Palaearctic Miltogrammatinae (Diptera: Sarcophagidae) with a description of a new genus. Dipt. Res. 5: 239-247.
WaLlman J.F. 2001: Third-instar larvae of common carrionbreeding blowflies of the genus Calliphora (Diptera: Calliphoridae). Invert. Taxon. 15: 37-51.

Zumpt F. 1965: Myiasis in Man and Animals in the Old World. A Textbook for Physicians, Veterinarians and Zoologists. Butterworth's, London, 267 pp.

Zumpt F. 1973: The genus Phylloteles (Diptera: Sarcophagidae, Miltogramminae) in Africa and Europe. Bull. Ann. Soc. R. Belge d'Entomol. 109: 308-319.

Received June 9, 2006; revised and accepted September 25, 2006 